\title{
Restriction enzyme analysis of DNA methylation in "condensed" chromatin of Ha-ras-transformed NIH 3T3 cells
}

\author{
Maria Luiza S. Mello ${ }^{\text {a,b,*, Ann F. Chambers }}{ }^{c}$, \\ Benedicto C. Vidal $^{\mathrm{a}, \mathrm{b}}$, Wolfgang Planding ${ }^{\mathrm{b}}$ and \\ Ulrich Schenck ${ }^{b}$ \\ ${ }^{a}$ Department of Cell Biology, Institute of Biology, \\ UNICAMP, 13083-970 Campinas, SP, Brazil \\ ${ }^{\mathrm{b}}$ Laboratory of Clinical Cytology, Institute of \\ Pathology, Technical University of Munich, \\ 81675 Munich, Germany \\ ${ }^{\mathrm{c}}$ Division of Experimental Oncology, Department of \\ Oncology, University of Western Ontario and London \\ Regional Cancer Centre, London, Ontario, Canada \\ N6A $4 L 6$
}

Received February 2000

Accepted 1 October 2000

Increased amounts of chromatin condensation (i.e., localized areas of high DNA density, or chromatin higher order packing state) have been described in NIH 3T3 cells transformed with the Ha-ras oncogene. The structural basis for this oncogene-mediated alteration in nuclear organization is unknown. Since DNA methylation is likely to be involved in regulating the nucleosomal level of DNA packaging, we studied the role of DNA methylation in higher-order chromatin organization induced by Ha-ras. CpG-methylated DNA content was estimated in "condensed" chromatin of Ha-ras-transformed NIH 3T3 cell lines which differ in ras expression and ras-induced metastatic ability but present approximately the same values of "condensed" chromatin areas. The question posed was that if DNA methylation were involved with the chromatin higher-order organization induced by Ha-ras in these cell lines, the methylated DNA density in the "condensed" chromatin would also be the same. The DNA evaluation was performed by video image analysis in Feulgen-stained cells previously subjected to treatment with Msp I and Hpa II restriction enzymes, which distinguish between methylated and non-methylated DNA. The amount of methylated CpG sequences not digested by Hpa II

\footnotetext{
${ }^{*}$ Corresponding author. Fax: +55 19 7887821; E-mail: mlsmello @ unicamp.br.
}

in "condensed" chromatin regions was found to vary in the studied ras-transformed cell lines. DNA CpG methylation status is thus suggested not to be involved with the higher order chromatin condensation induced by ras transformation in the mentioned NIH 3 T3 cell lines.

Keywords: Chromatin higher-order condensation, Ha-ras, DNA methylation, restriction endonucleases, image analysis

\section{Introduction}

NIH 3T3 cells transformed by the Ha-ras oncogene exhibit increased levels of chromatin "condensation" in interphase nuclei as assessed by Feulgen staining and image analysis $[19,20,22]$. These changes are independent of the level of oncogenic ras expression and of ras-induced metastatic ability [19], but are at least in part affected by the expression of a ras recision gene (lysyl oxidase, Lox) [22]. Furthermore, the rasassociated changes involving chromatin higher order packing states in rodent fibroblast cell lines were recently demonstrated to be independent of their mitotic signaling pathway [9].

Although enhancement in interphase chromatin higher order packing state is well evident in rastransformed NIH 3T3 cell preparations observed by the light microscope and with video image analyzers [19$22]$, biochemical data have suggested that a more decondensed nucleosomal state occurs in the chromatin of these ras-transformed cells [13].

In other cell systems such as benzo[a]pyrene-transformed human breast epithelial cells, progressive changes in chromatin "condensation" have been demonstrated by image analysis [29]. These changes accompany genomic alterations characteristic of the in vitro multistep tumorigenic process [29] and were associated with nucleolar changes suggesting enhanced metabolic activities [3]. In the particular case of these transformed cells the condensed chromatin areas observed under the microscope were thus interpreted 
to represent an assembly of chromatin regions which could be defined as presenting decondensation at the nucleosomal level [29].

One possible explanation for changes in condensed chromatin states affecting many chromosomal domains is different degrees of DNA methylation [8,17]. DNA methylation has been reported to be associated with carcinogenesis through various mechanisms $[2,4$, $12,16,27]$. In NIH 3 T3 cells particularly, overexpression of cytosine (DNA-5)-methyltransferase leads to transformation [30]. In other cell systems, hypomethylation of proto-oncogenes and hypermethylation of tumor suppressor genes alter the expression levels of these genes, providing an epigenetic model for tumor development $[12,27]$.

On the other hand, higher order chromatin organization (=supraorganization) is affected by nuclear matrix proteins $[6,9,15,25]$, which might be advantageous to increase transcriptional efficiency and interactions facilitated by the proximity of active chromatin domains [26].

If DNA methylation were associated with chromatin supraorganization in the Ha-ras-transformed NIH 3T3 cell lines differing in ras expression and ras-induced metastatic ability, little variation in methylated DNA would occur since "condensed" chromatin areas and DNA values practically do not vary in these cell lines [19].

The participation of DNA methylation in "condensed" chromatin areas could be estimated in situ through video image analysis of Feulgen-DNA values after restriction enzyme treatment of these cells with either Msp I or Hpa II. Msp I and Hpa II are isoschizomeric restriction enzymes which cleave the base sequence -CCGG-, Hpa II being sensitive to methylation of the internal $\mathrm{CpG}$ dinucleotide [24]. In other words, Hpa II cuts the sequence CCGG but fails to cleave it if the central $\mathrm{C}$ is methylated. It has been demonstrated by digital image analysis that restriction enzymes may recognize, cleave and remove DNA from fixed chromosomes, giving rise to enzyme-specific images [10].

Although Msp I and Hpa II are considered useful tools for mitotic chromosome banding methods [23, 28 ], they have not been applied up to now to whole interphase nucleus studies. Since the present investigation is centered on "condensed" chromatin areas and interphase heterochromatin is as condensed as are mitotic chromosomes [15,17], Msp I and Hpa II may also be suitable to interphase chromatin studies especially after acetic ethanol fixation (which extracts many cell proteins), and extending digestion time for as long as the longest period proposed for mitotic chromosomes [23,28].

Here we determined by image analysis that the amount of methylated DNA in the "condensed" chromatin of interphase cell nuclei varied with the Ha-rastransformed NIH 3T3 cell line, leading us to assume that methylated $\mathrm{CpG}$ sequences are not related to chromatin higher order condensation enhancement with ras transformation.

\section{Materials and methods}

\subsection{Cells}

A series of T24 Ha-ras oncogene-transformed NIH $3 \mathrm{~T} 3$ cell lines previously isolated and characterized [7, 11], as well as control NIH 3T3 cells, were grown in Dulbecco's modified Eagle medium (Grand Island Biological Co., Grand Island, New York, USA) with 10\% calf serum (Grand Island). All the ras-transformed cells used are tumorigenic but differ in the levels of oncogenic ras protein expression and metastatic ability. The cell lines used were as follows:

C2P2, C5P2: lines derived from $\mathrm{C} 2 \mathrm{P} 0$ and $\mathrm{C} 5 \mathrm{P} 0$ clonal ras-transformed NIH 3T3 cells, respectively. C2P0 and C5P0 cells express very low levels of ras p21 protein, similar to those expressed by nontransformed NIH 3T3 cells, and are poorly metastatic, although tumorigenic. The $\mathrm{C} 2 \mathrm{P} 2$ and $\mathrm{C} 5 \mathrm{P} 2$ lines show increased metastatic ability in both chick embryos and nude mice and have higher proportions of ras protein expressing cells.

PAP2: cell line derived from PAP0 nonclonal, pooled population of ras-transformed NIH 3 T3 cells, and selected in vivo for increased metastatic ability in both chick embryo and nude mice. PAP2 cells have a higher proportion of oncogenic ras protein-expressing cells compared to PAP0 cells.

NIH 3T3: nontumorigenic, nonmetastatic, control cells that express low levels of normal ras protein.

\subsection{Cell preparations}

Control and ras-transformed cells grown on coverslips were fixed in an absolute ethanol-acetic acid mixture $(3: 1)$ for one minute, rinsed in $70 \%$ ethanol for five minutes and air dried at room temperature. 


\subsection{Restriction enzymes}

Digestions with $M s p$ I and Hpa II from Amersham Pharmacia Biotech AB (Uppsala, Sweden) and Gibco BRL (Gaithersburg, MD, USA), respectively, were performed. Enzyme solutions were prepared according to conditions suggested by the supplier, at a final concentration of $0.5 \mathrm{U} / \mu \mathrm{l}$. Coverslips of each cell line were covered with each enzyme solution. Incubations were carried out in a moist chamber at $37^{\circ} \mathrm{C}$ for $16 \mathrm{~h}[23$, 28 ] and halted by rinsing the coverslips in stop buffer and assay buffer. Control preparations were incubated in the appropriate buffer without enzyme. Two sets of each cell line were used for each enzyme treatment and respective control.

\subsection{Staining procedure}

The preparations were subjected to the Feulgen reaction (4 $\mathrm{N} \mathrm{HCl}$ at $25^{\circ} \mathrm{C}, 80 \mathrm{~min}$; Schiff reagent, $1 \mathrm{~h}$ ) and mounted in Canada balsam $\left(n_{\mathrm{D}}=1.54\right)$ [18].

\subsection{Video image analysis}

Zeiss-Kontron (Oberkochen-Munich, Germany) equipment was used for image acquisition, segmentation and featuring, by means of the Kontron-IPS system and appropriate programs according to the Kontron-IBAS 2000 manual of instructions [21,22].

The microscopic images were observed under a Zeiss (Oberkochen, Germany) Universal N microscope with a Neofluar 100/1.30 objective, optovar 1.25, 1.3 condenser, and $\lambda=565 \mathrm{~nm}$. The images to be processed were fed from the microscope into the computer through a monochrome CCD (Hamamatsu C3077) video camera. In this investigation, $1 \mu \mathrm{m}=11.3$ pixels.

A software macro developed by one of us (W.P.) provided quantitative morphological information on chromatin texture [21,22]. Different grey levels were assigned colors, for ease of display. After transformation of the original image, measurement inside the segmented object from the transformed image was carried out. Since densitometric features were derived from whole nuclei as well as from "condensed" chromatin regions, two segmentation levels were used. Although interactive image editing was possible during the run of the program, it was rarely required for the nuclei analyzed here.

Image analysis parameters pertinent to this study were:
1. $A_{\mathrm{T}}$, total integrated absorbance (= nuclear Feulgen-DNA values);

2. $A_{\mathrm{c}}$, integrated absorbance over a preselected absorbance threshold which was established for control nontransformed cell nuclei (type I nuclei) treated only with buffer. The same threshold level was automatically maintained for analysis of the nuclei with the other phenotypes and under enzyme treatment conditions. $A_{\mathrm{c}}$ corresponds to "condensed" chromatin Feulgen-DNA values; and

3. $A_{\mathrm{c}} \%$, "condensed" chromatin Feulgen-DNA values relative to the nuclear (whole chromatin) Feulgen-DNA values.

Two hundred nuclei of each phenotype were measured for each cell line and experimental condition. One hundred nuclei were evaluated in each coverslip preparation. Data were analyzed statistically (descriptive statistics and nonparametrics) using the Minitab ${ }^{\circledR}$ statistical software for Windows (Minitab Inc., State College, PA, USA).

\section{Results}

\subsection{Nuclear phenotypes}

Nuclei from each cell type were characterized as previously described [19,20,22]. Briefly, the nuclear phenotypes observed are: I, I' - nuclei containing a few small granules of stained chromatin against a pale background; II - nuclei with abundant small granules of deeply stained chromatin; and III - nuclei with extensive areas of deeply stained coarse chromatin. Phenotypes I and II are present in nontransformed NIH 3T3 cells whereas phenotypes I' and III appear in the transformed cells. Nuclei with another phenotype, characterized by a few coarse and wellcircumscribed chromatin granules against a very pale background (IV) and present at low frequency in the ras-transformed cells $(<1.3 \%$ [19]), when detected, were added to the $\mathrm{I}^{\prime}$ phenotype group due to their morphological similarity. Figure 1 shows examples of nuclei studied with the video image analysis system and photographed from the color monitor. Since "condensed" chromatin Feulgen-DNA relative values $\left(A_{\mathrm{c}} \%\right)$ are the goal of present investigation, there was no preocupation with selecting identical absolute nuclear sizes to show here. 



Fig. 1. Examples of pseudocolorized images of Feulgen-stained type I nuclei (NIH 3T3 cells) (a-d) and type III nuclei (C5P2 cells) (e-h) subjected to $M s p \mathrm{I}(\mathrm{b}, \mathrm{f})$ and $H p a \mathrm{II}(\mathrm{d}, \mathrm{h})$ treatments prior to staining, and photographed from the color monitor. Respective buffer-only controls, a, c, e, g. 


\subsection{Total Feulgen-DNA content}

The distribution of the total nuclear Feulgen-DNA values $\left(A_{\mathrm{T}}\right)$ for type II (III) relative to $\mathrm{I}\left(\mathrm{I}^{\prime}\right)$ nuclei in nontransformed and ras-transformed cells after treatment with buffer alone (data not shown) was found to be in agreement with Mello and Chambers' [19] previous data for untreated cells. The Feulgen-DNA absolute values obtained for controls simply incubated in buffers differed from each other, when the two groups of assays were compared, a result attributed to different actions on chromatin of buffers which differed in composition [5]. For this reason, buffer-only treatment provides the appropriate control.

Total Feulgen-DNA content was not used for comparisons between buffer- and enzyme-treated cells since different ploidy degrees are found simultaneously in interphase nuclei of the different cell lines [19].

\section{3. "Condensed" chromatin Feulgen-DNA content}

$A_{\mathrm{c}} \%$ values were used for comparisons since they were not affected by nuclear ploidy degrees [19]. The $A_{\mathrm{c}} \%$ values in the untreated ras-transformed cells analyzed here were found not to differ (Fig. 2). After Msp I treatment the $A_{\mathrm{c}} \%$ values for all cell types and nuclear phenotypes in comparison with buffer-only condition decreased (Fig. 3, Table 1). The values for buffer- and Msp I-treated type III nuclei of PAP2, C2P2 and C5P2 cells were found to differ significantly (Table 2). While the values for $\mathrm{C} 2 \mathrm{P} 2$ and $\mathrm{C} 5 \mathrm{P} 2$ cells compared to each other were found to differ in buffer- and Msp I-treated cells, the values for PAP2 cells differed from those of C5P2 cells in buffer-treated preparations but not in $M s p$ I-treated cells (Table 2). Also the $A_{\mathrm{c}} \%$ values of $M s p$ I-treated type I' nuclei of PAP2 and C5P2 cells were found not to differ (Table 2), although those of buffertreated preparations differed (Fig. 3).

After the $\mathrm{Hpa}$ II treatment a decrease in $A_{\mathrm{c}} \%$ values was observed in all nontransformed NIH 3 T3 cell nuclei and in type III nuclei of C5P2 cells. The other nuclear types did not show differences in $A_{\mathrm{c}} \%$ values after enzyme treatment or, in the case of type III nuclei of C2P2 cells and type I' nuclei of C5P2 cells, even larger values were exhibited (Fig. 4, Table 1 ). The $A_{\mathrm{c}} \%$ values of type $\mathrm{I}^{\prime}$ and III nuclei of $\mathrm{C} 2 \mathrm{P} 2$ cells compared to those of C5P2 cells were found not to differ in buffertreated preparations (Table 3 ). When comparing the $A_{\mathrm{c}} \%$ values for $\mathrm{Hpa}$ II-treated C2P2 and C5P2 cells a difference was demonstrated only for type III nuclei

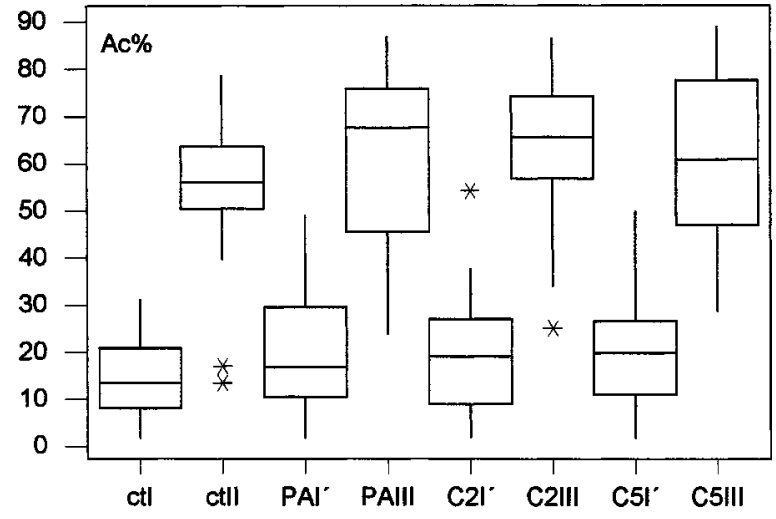

Fig. 2. Tukey's box-and-whisker plots (descriptive statistics, Mini$\mathrm{tab}^{\circledR}$ statistical software) for "condensed" chromatin Feulgen-DNA relative values $\left(A_{\mathrm{c}} \%\right)$ of nontransformed and ras-transformed $\mathrm{NIH}$ $3 \mathrm{~T} 3$ cells. Lower and upper traces $=$ lower and upper quartiles of the distributions; middle trace $=$ median; $*$, outliers; ct, control nontransformed cells; C2, C2P2 cells; C5, C5P2 cells; PA, PAP2 cells; I, I', II, and III, nuclear phenotypes. $n=200$.

(Table 3). The $A_{\mathrm{c}} \%$ values of PAP2 and C5P2 type III nuclei, which differed under buffer treatment conditions, no longer differed after the Hpa II treatment, similarly as observed after the Msp I treatment (Tables 2, 3). Type I' nuclei of PAP2 and C5P2 cells were found not to differ from each other in either buffer- or Hpa II treatment conditions (Table 3).

\section{Discussion}

The results presented here indicate that methylated and unmethylated -CCGG- sequences occurring in the chromatin of NIH $3 \mathrm{~T} 3$ cell lines treated with restriction enzymes could be determined when Feulgen-DNA values for "condensed" chromatin $\left(A_{\mathrm{c}} \%\right)$ are studied in situ by image analysis.

The threshold level selected for consideration of "condensed" chromatin was the same used for discriminating this chromatin in untreated preparations of NIH 3T3 type I nuclei. It is reasonably comparable to a cut off point equal to absorbance 0.350 in a Zeiss automatic scanning microspectrophotometer. The morphological images of the "condensed" chromatin in NIH 3T3 type I nuclei under buffer-only condition as shown here (Fig. 1a,c) match well with those in Figs. 1a/1b and Fig. 1a from previously published reports for untreated cells ([21] and [22], respectively).

Since $A_{\mathrm{c}} \%$ values decreased with Msp I while remaining unchanged with Hpa II in nuclei with the same phenotype in some of the transformed cell lines, 

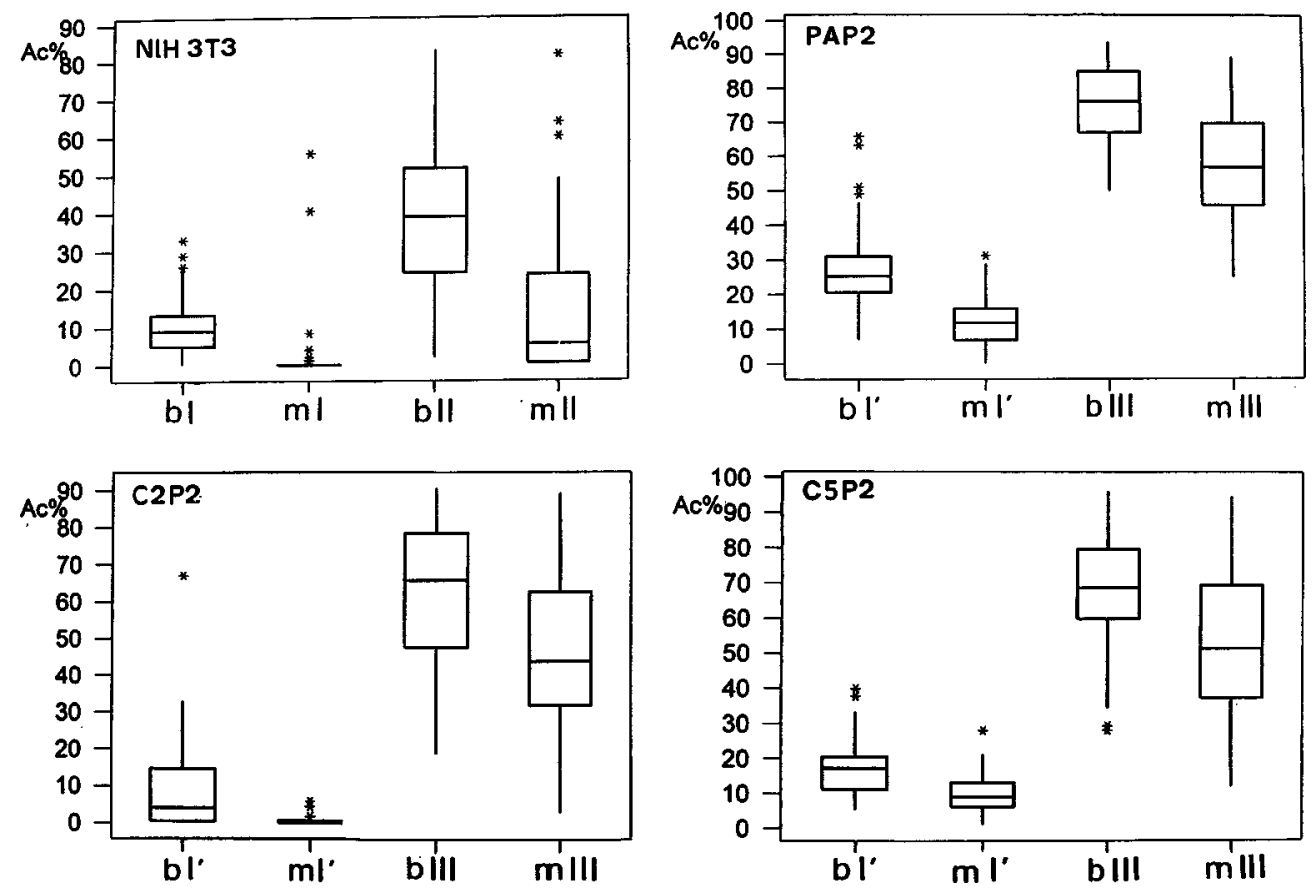

Fig. 3. Tukey's box-and-whisker plots (descriptive statistics, Minitab ${ }^{\circledR}$ statistical software) for "condensed" chromatin Feulgen-DNA relative values $\left(A_{\mathrm{c}} \%\right)$ for nontransformed and ras-transformed NIH 3 T3 cells. Preparations treated with $M s p \mathrm{I}$ (m) or just the $M s p$ I buffer (b). Lower and upper traces $=$ lower and upper quartiles of the distributions; middle trace = median; *, outliers; I, I' ${ }^{\prime}$ II, and III, nuclear phenotypes. $n=200$.

Table 1

Mann-Whitney test for "condensed" chromatin Feulgen-DNA content $\left(A_{\mathrm{c}} \%\right)$ comparisons (Minitab ${ }^{\circledR}$ statistical software)

\begin{tabular}{|c|c|c|c|}
\hline \multirow[t]{3}{*}{ Cells } & \multirow{3}{*}{$\begin{array}{c}\text { Nuclear } \\
\text { phenotypes }\end{array}$} & \multicolumn{2}{|c|}{ Conditions compared } \\
\hline & & $\mathrm{M}$ & $\mathrm{H}$ \\
\hline & & $(p)$ & $(p)$ \\
\hline \multirow[t]{2}{*}{ NIH 3T3 } & $\mathrm{I}$ & $0.0000^{* *}$ & $0.0000^{* *}$ \\
\hline & II & $0.0000^{* *}$ & $0.0000^{* *}$ \\
\hline \multirow[t]{2}{*}{ PAP2 } & $\mathrm{I}^{\prime}$ & $0.0000^{* *}$ & 0.1016 \\
\hline & III & $0.0000^{* *}$ & 0.1425 \\
\hline \multirow[t]{2}{*}{$\mathrm{C} 2 \mathrm{P} 2$} & $\mathrm{I}^{\prime}$ & $0.0000^{* *}$ & 0.3804 \\
\hline & III & $0.0000^{* *}$ & $0.0000^{* *}$ \\
\hline \multirow[t]{2}{*}{$\mathrm{C} 5 \mathrm{P} 2$} & $\mathrm{I}^{\prime}$ & $0.0000^{* *}$ & $0.0032^{* *}$ \\
\hline & III & $0.0000^{* *}$ & $0.0000^{* *}$ \\
\hline
\end{tabular}

H, Hpa II vs. respective buffer; M, Msp I vs. respective buffer;

**, highly significant $\left(P_{0.01}\right) ; n=200$.

it is suggested that both methylated and unmethylated -CCGG- sites can co-exist in the "condensed" chromatin of the ras-transformed cells. If Msp I were unable to digest methylated $\mathrm{CpG}$ islands because intact nuclei were used here [1], Msp I and Hpa II digestion should give rise to similar results, which was not the case.

The variable decrease in $A_{\mathrm{c}} \%$ values with $M s p$ I in the various NIH $3 \mathrm{~T} 3$ cell lines indicates that the un- methylated $\mathrm{CpG}$ sequences removed with this enzyme varied in amount with the cell line and the nuclear phenotype considered, being more abundant in the "condensed" chromatin of the nontransformed (control) cells. Methylated $\mathrm{CpG}$ sequences, on the other hand, were more frequent in the "condensed" chromatin of the ras-transformed cells but not equally abundant in the different cell lines.

Presence of unmethylated as well as of moderate to high levels of methylated $\mathrm{CpG}$ islands has been previously reported in nontransformed NIH 3T3 cells [1]. Hypermethylation in this case was considered to involve genes that mediate differentiation rather than genes essential for cell viability [1]. If de novo $\mathrm{CpG}$ methylation in transformed NIH 3T3 cells is confined to genes whose products are not essential under culture conditions, the variable response to $\mathrm{Msp} \mathrm{I} / \mathrm{Hpa}$ II enzymes in the "condensed" chromatin of different ras-transformed NIH 3T3 cell lines as found here may mean that different changes in the expression of genes required for survival were acquired with ras transformation.

It should be mentioned that $A_{\mathrm{c}} \%$ values of $\mathrm{Hpa}$ II buffer-treated nuclei were smaller than those of Msp I buffer-treated nuclei in ras-transformed cells. It is possible that the incubation in the assay buffers (espe- 
Table 2

"Condensed" chromatin Feulgen-DNA content $\left(A_{\mathrm{c}} \%\right)$ comparisons among ras-transformed nuclei (Minitab ${ }^{\circledR}$ statistical software)

\begin{tabular}{|c|c|c|c|c|}
\hline Cells compared & $\begin{array}{c}\text { Nuclear } \\
\text { phenotypes }\end{array}$ & Treatment & Nonparametric tests & Conclusion \\
\hline \multirow[t]{2}{*}{ PAP2, C2P2, C5P2 } & III & buffer & Kruskal-Wallis & $\begin{array}{l}H=25.76, \text { d.f. }=2, \\
p=0.000 \text { (adjusted for ties) }^{* *}\end{array}$ \\
\hline & & $M s p \mathrm{I}$ & Kruskal-Wallis & $\begin{array}{l}H=16.54, \text { d.f. }=2 \\
p=0.000 \text { (adjusted for ties) }\end{array}$ \\
\hline \multirow[t]{2}{*}{$\mathrm{C} 2 \mathrm{P} 2, \mathrm{C} 5 \mathrm{P} 2$} & III & buffer & Mann-Whitney & $p=0.0488$ \\
\hline & & Msp I & Mann-Whitney & $p=0.0226^{*}$ \\
\hline \multirow[t]{3}{*}{ PAP2, C5P2 } & $\mathrm{I}^{\prime}$ & Msp I & Mann-Whitney & $p=0.0527$ \\
\hline & III & buffer & Mann-Whitney & $p=0.0006^{* *}$ \\
\hline & & Msp I & Mann-Whitney & $p=0.0672$ \\
\hline
\end{tabular}

*, significant $\left(P_{0.05}\right) ;{ }^{* *}$, highly significant $\left(P_{0.01}\right) ; n=200$.
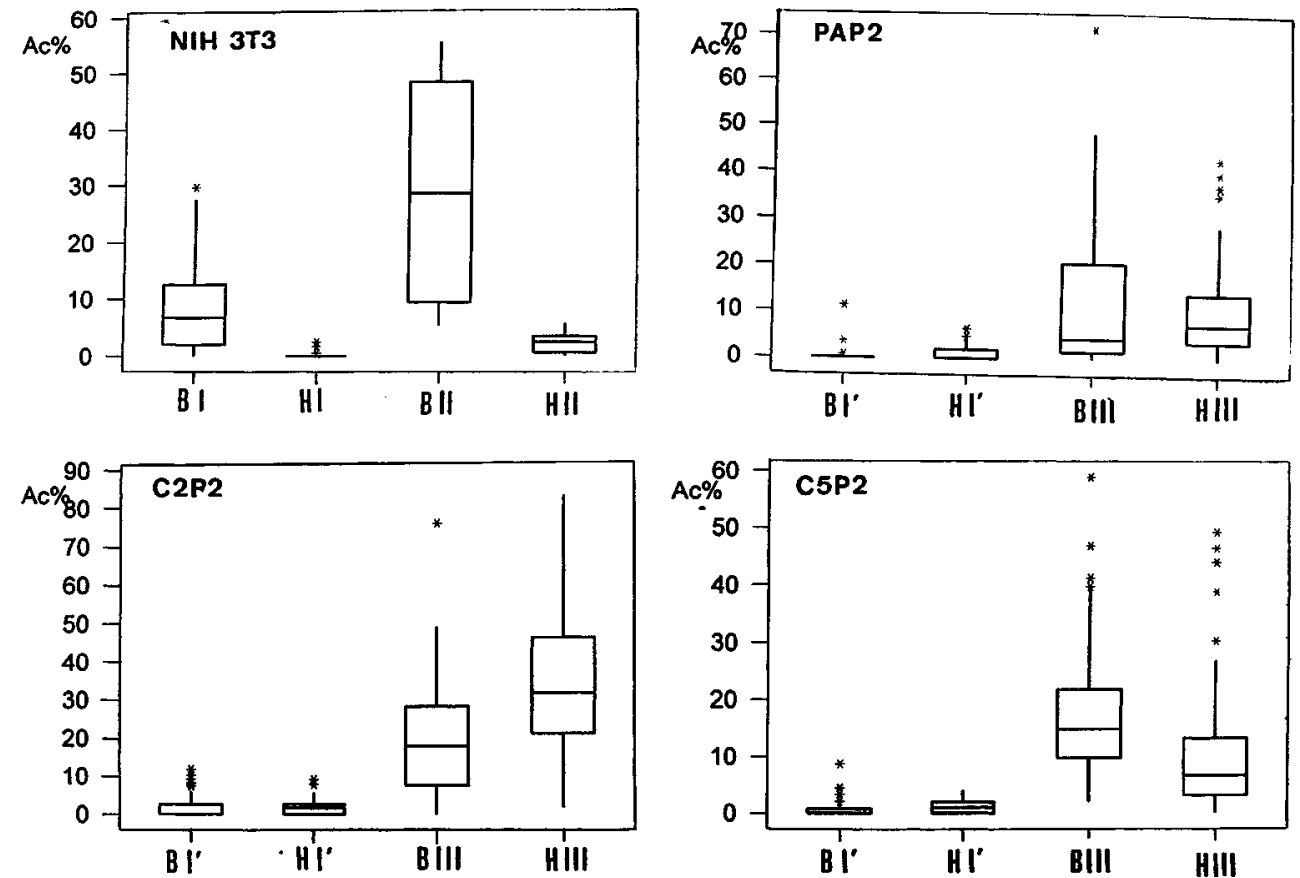

Fig. 4. Tukey's box-and-whisker plots (descriptive statistics, Minitab ${ }^{\circledR}$ statistical software) for "condensed" chromatin Feulgen-DNA relative values $\left(A_{\mathrm{c}} \%\right)$ for nontransformed and ras-transformed NIH 3T3 cells. Preparations treated with Hpa II (H) or just the Hpa II buffer (B). Lower and upper traces $=$ lower and upper quartiles of the distributions; middle trace = median; *, outliers; I, I', II, and III, nuclear phenotypes. $n=200$.

cially, Hpa II buffer), induces some conformational change in the chromatin [5] causing earlier solubilization of part of the apurinic acid with Feulgen's acid hydrolysis [18]. When the assay buffer was supplemented with $\mathrm{Hpa}$ II, additional conformational changes might be introduced in the chromatin, delaying the abovementioned step of the Feulgen kinetics. Such being the case, Hpa II assay buffer and enzyme actions would have been selective for the ras-transformed cells. Furthermore, this hypothesis may explain the increase in $A_{\mathrm{c}} \%$ values for some nuclear types of the rastransformed NIH 3T3 cells after Hpa II treatment.

The results obtained after the restriction enzyme treatments for the areas with increased chromatin higher order condensation varied in the different rastransformed NIH 3T3 cell lines. Since the "condensed" chromatin areas and their corresponding DNA amounts differ little in the cell lines tested [19, Fig. 2], but do differ in their response to Hpa II treatment, it is assumed that $\mathrm{CpG}$ methylation may not be equally 
Table 3

Mann-Whitney test for "condensed" chromatin Feulgen-DNA content $\left(A_{\mathrm{c}} \%\right)$ comparisons (Minitab ${ }^{\circledR}$ statistical software)

\begin{tabular}{lccl}
\hline $\begin{array}{l}\text { Cells } \\
\text { compared }\end{array}$ & $\begin{array}{c}\text { Nuclear } \\
\text { phenotypes }\end{array}$ & Treatment & Conclusion \\
\hline C2P2, C5P2 & I $^{\prime}$ & none & $p=0.8659$ \\
& buffer & $p=0.1631$ \\
& Hpa II & $p=0.4957$ \\
III & none & $p=0.4524$ \\
& buffer & $p=0.6868$ \\
PAP2, C5P2 & Hpa II & $p=0.0000^{* *}$ \\
& none & $p=0.8795$ \\
& I' & buffer & $p=0.1508$ \\
& Hpa II & $p=0.3454$ \\
& none & $p=0.6221$ \\
& III & buffer & $p=0.0000^{* *}$ \\
& Hpa II & $p=0.4822$ \\
\hline
\end{tabular}

**, highly significant $\left(P_{0.01}\right) ; n=200$.

present in the highly packed chromatin with ras transformation.

As a conclusion, it is suggested that methylated $\mathrm{CpG}$ DNA sequences are not associated with the chromatin condensation enhancement that accompanies ras transformation in NIH $3 \mathrm{~T} 3$ cells, since the enhanced amount of methylated DNA detected in the "condensed" chromatin of these cells was found to vary with the cell line considered and not to accompany the invariable amount of chromatin condensation of the transformed cell lines. This idea is supported by a report demonstrating that DNA methylation is not involved with the structural organization at the molecular level of the ornithine decarboxylase gene and the bulk chromatin in c-Ha-ras ${ }^{(\mathrm{Val}-12)}$ oncogene-transformed NIH 3T3 cells [14].

\section{Acknowledgments}

This study was supported by grants from the Brazilian National R \& D Council (CNPq), the São Paulo State Research Support Foundation (FAPESP), the Alexander von Humboldt Foundation, the State University of Campinas Research Support Foundation (FAEP/UNICAMP), and the National Cancer Institute of Canada. The authors are indebted to Dr. Andrew $\mathrm{H}$. Fischer (Emory University Hospital, Atlanta, USA) for criticism and helpful suggestions.

\section{References}

[1] F. Antequera, J. Boyes and A. Bird, High levels of de novo methylation and altered chromatin structure at $\mathrm{CpG}$ islands in cell lines, Cell 62 (1990), 503-514.

[2] A. Balmain, Exploring the bowels of DNA methylation, Curr. Biol. 5 (1995), 1813-1816.

[3] L.F. Barbisan, J. Russo and M.L.S. Mello, Nuclear and nucleolar image analysis of human breast epithelial cells transformed by benzo[a]pyrene and transfected with the c-Ha-ras oncogene, Anal. Cell. Pathol. 16 (1998), 193-199.

[4] S.B. Baylin, Tying it all together: epigenetics, genetics, cell cycle, and cancer, Science (Washington) 277 (1997), 1948-1949.

[5] N.O. Bianchi, W.F. Morgan and J.E. Cleaver, Relationship of ultraviolet light-induced DNA-protein cross-linkage to chromatin structure, Exptl Cell Res. 156 (1985), 405-418.

[6] D.N. Chadee, W.R. Taylor, R.A.R. Hurta, C.D. Allis, J.A. Wright and J.R. Davie, Increased phosphorylation of histone $\mathrm{H} 1$ in mouse fibroblasts transformed with oncogenes or constitutively active mitogen-activated protein kinase kinase, J. Biol. Chem. 270 (1995), 20 098-20 105.

[7] A.F. Chambers, G.H. Denhardt and S.M. Wilson, Rastransformed NIH 3T3 cell lines selected for metastatic ability in chick embryos, have increased proportions of p21 expressing cells and are metastatic in nude mice, Invasion Metastasis 10 (1990), 225-240.

[8] J.F. Costello, M.S. Berger, H.J.S. Huang and W.K. Cavenee, Silencing of $p 16 / C D K N 2$ expression in human gliomas by methylation and chromatin condensation, Cancer Res. 56 (1996), 2405-2410.

[9] A.H. Fischer, D.N. Chadee, J.A. Wright, T.S. Gansler and J.R. Davie, Ras-associated nuclear structural change appears functionally significant and independent of the mitotic signaling pathway, J. Cell Biochem. 70 (1998), 130-140.

[10] J. Gosalvez, C. López-Fernández, J.L. Fernández, J. Goyanes and I. Buño, Digital image analysis of chromatin fibre phenotype after "in situ" digestion with restriction endonucleases, Cell Biol. Int. 19 (1995), 827-832.

[11] S.A. Hill, S. Wilson and A.F. Chambers, Clonal heterogeneity, experimental metastatic ability, and $\mathrm{p} 21$ expression in $\mathrm{H}$-ras -transformed NIH 3 T3 cells, J. Natl. Cancer Inst. 80 (1988), 484-490.

[12] P.A. Jones and J.D. Buckley, The role of DNA methylation in cancer, Adv. Cancer Res. 54 (1990), 1-23.

[13] J. Laitinen, L. Sistonen, K. Alitalo and E. Hölttä, c-Ha-ras Val12 oncogene-transformed NIH-3T3 fibroblasts display more decondensed nucleosomal organization than normal fibroblasts, J. Cell Biol. 111 (1990), 9-17.

[14] J. Laitinen, P. Saris and E. Holtta, DNA methylation is not involved in the structural alterations of ornithine decarboxylase or total chromatin of c-Ha-ras(Val-12) oncogene-transformed NIH-3T3 fibroblasts, J. Cell Biochem. 57 (1995), 670-679.

[15] M.E.E. Ludérus and R. van Driel, Nuclear Organization, Chromatin Structure, and Gene Expression, R. van Driel and A.P. Otte, eds, Oxford Univ. Press, Oxford, 1997, pp. 99-115.

[16] A.R. MacLeod, J. Rouleau and M. Szyf, Regulation of DNA methylation by the ras signaling pathway, J. Biol. Chem. 270 (1995), 11327-11337. 
[17] L. Manuelidis, A view of interphase chromosomes, Science (Washington) 250 (1990), 1533-1540.

[18] M.L.S. Mello, Cytochemistry of DNA, RNA and nuclear proteins, Braz. J. Genet. 20 (1997), 257-264.

[19] M.L.S. Mello and A.F. Chambers, Image analysis of Feulgenstained transformed NIH 3T3 cells differing in p21 expression and ras-induced metastatic ability, Analyt. Quant. Cytol. Histol. 16 (1994), 113-123.

[20] M.L.S. Mello and J. Russo, Image analysis of Feulgen-stained c-H-ras-transformed NIH/3T3 cells, Biochem. Cell Biol. 68 (1990), 1026-1031.

[21] M.L.S. Mello, B.C. Vidal, W. Planding and U. Schenck, Image analysis: video system adequacy for the assortment of nuclear phenotypes based on chromatin texture evaluation, Acta Histochem. Cytochem. 27 (1994), 23-31.

[22] M.L.S. Mello, S. Contente, B.C. Vidal, W. Planding and U. Schenck, Modulation of ras transformation affecting chromatin supraorganization as assessed by image analysis, Exp. Cell Res. 220 (1995), 374-382.

[23] R. Mezzanotte, U. Bianchi, R. Vanni and L. Ferruci, Chromatin organization and restriction endonuclease activity on human metaphase chromosomes, Cytogenet. Cell Genet. 36 (1983), 562-566.

[24] M. Nelson and M. McClelland, Site-specific methylation effect on DNA modification methyltransferases and restriction endonucleases, Nucleic Acids Res. 19 (1991), 2045-2071.
[25] S.K. Samuel, T.M. Minish and J.R. Davie, Altered nuclear matrix protein profiles in oncogene-transformed mouse fibroblasts exhibiting high metastatic potential, Cancer Res. 57 (1997), $147-151$.

[26] P. Schedl and F. Grosveld, Domains and boundaries, in: Chromatin Structure and Gene Expression, S.C.R. Elgin, ed., IRL Press, Oxford, 1995, pp. 172-196.

[27] C. Schmutte, A.S. Yang, T.T. Nguyen, B.W. Beart and P.A. Jones, Mechanisms for the involvement of DNA methylation in colon carcinogenesis, Cancer Res. 56 (1996), 2375-2381.

[28] C. Sentis, J. Santos and J. Fernandez-Piqueras, Breaking up the chromosomes of Baetica ustulata by in situ treatments with restriction endonucleases, Genome 32 (1989), 208-215.

[29] B.C. Vidal, J. Russo and M.L.S. Mello, DNA content and chromatin texture of benzo[a]pyrene-transformed human breast epithelial cells as assessed by image analysis, Exptl Cell Res. 244 (1998), 77-82.

[30] J. Wu, J.P. Issa, J. Herman, D.J. Bassett, B.D. Nelkin and S.B. Baylin, Expression of an exogenous eukaryotic DNA methyltransferase gene induces transformation of NIH 3T3 cells, Proc. Natl. Acad. Sci. USA 90 (1993), 8891-8895. 


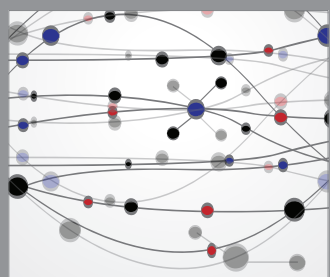

The Scientific World Journal
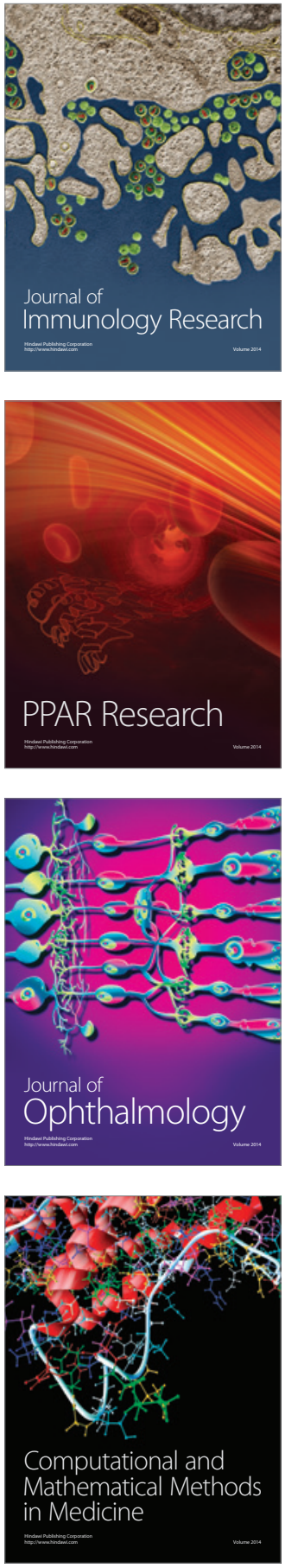

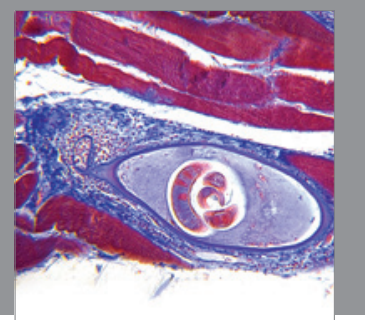

Gastroenterology

Research and Practice
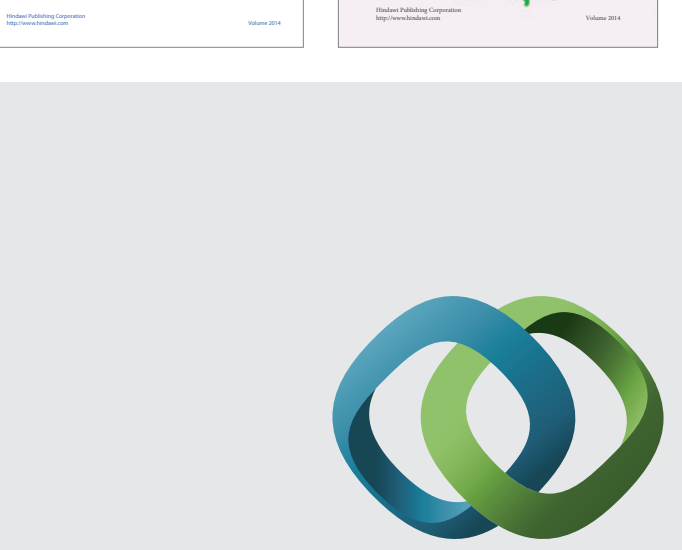

\section{Hindawi}

Submit your manuscripts at

http://www.hindawi.com
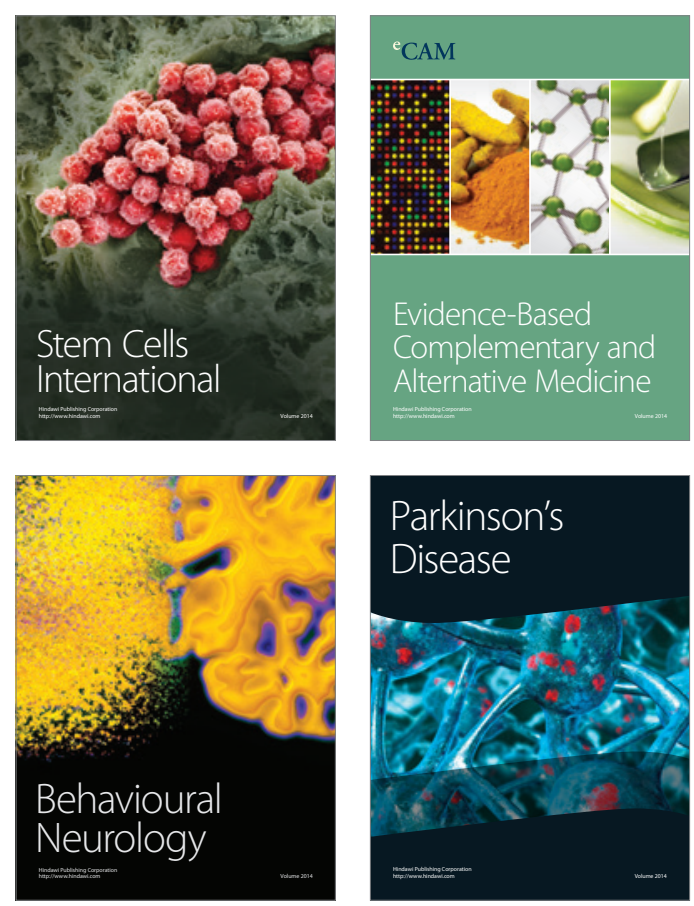

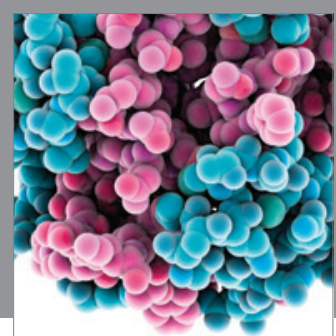

Journal of
Diabetes Research



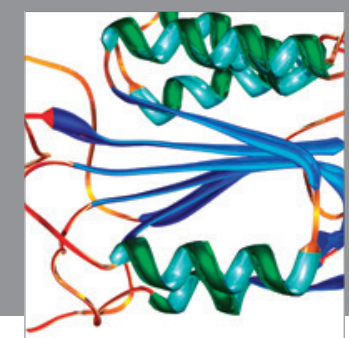

Disease Markers
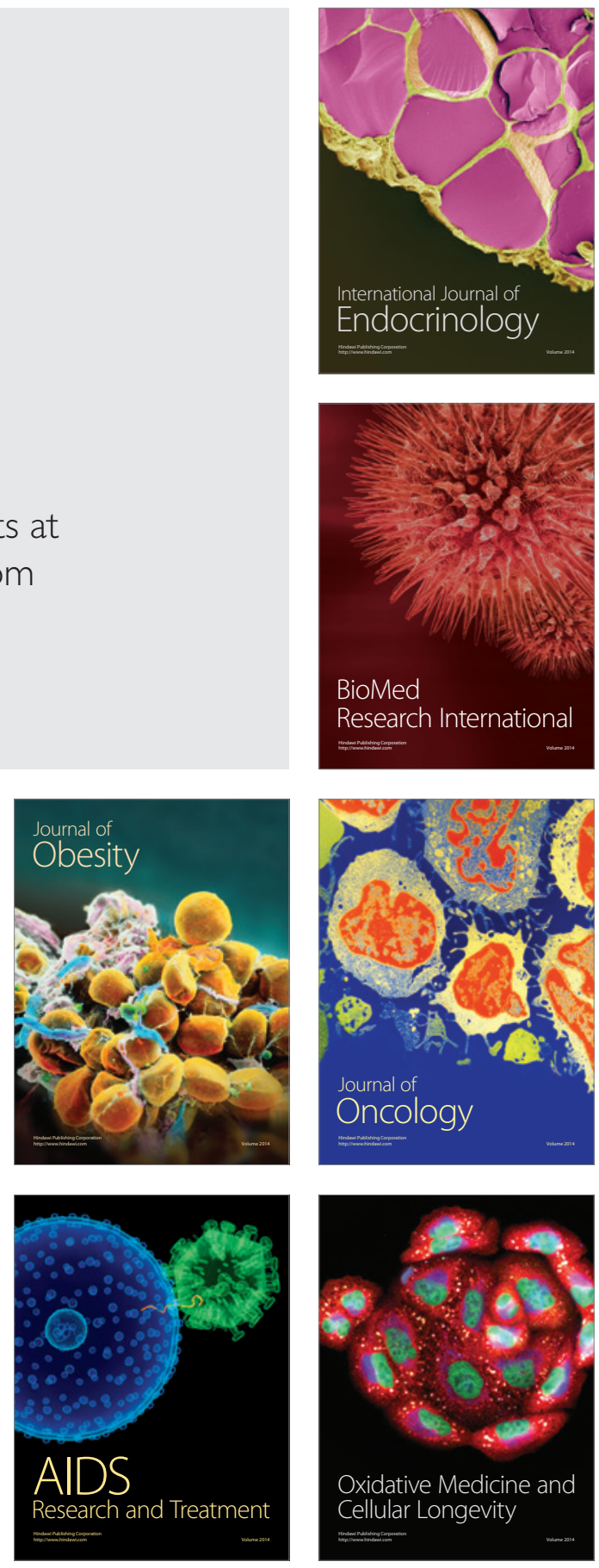